\title{
Shiga (Vero)-toxin producing Escherichia coli isolated from the hospital foods; virulence factors, o-serogroups and antimicrobial resistance properties
}

Reza Ranjbar', Mojtaba Masoudimanesh², Farhad Safarpoor Dehkordi ${ }^{3}$ Nematollah Jonaidi-Jafari ${ }^{4^{*}}$ and Ebrahim Rahimi ${ }^{5}$

\begin{abstract}
Background: According to the presence of the weak, diabetic and immunosuppressive patients in hospitals, hospital foods should have a high quality and safety. Cooking a lot of foods higher than daily requirement, storage of cooked foods in an inappropriate condition and presence of nurses and servants in distribution of food to patients are the main reasons caused contamination of hospital foods. Shiga toxigenic Escherichia coli is one of the common cause of food poisoning in hospitals. The present research was carried out to study the distribution of virulence factors, O-serogroups and antibiotic resistance properties in STEC strains recovered from Iranian hospital food samples.

Methods: Five-hundred and eighty raw and cooked food samples were collected and immediately transferred to the laboratory. E. coli-positive strains were subjected to PCR and disk diffusion method.

Results: Thirty-nine out of 580 (6.72\%) hospital food samples were contaminated with E. coli. Raw (20\%) and cooked meat (6\%) were the most commonly contaminated samples. Raw samples had the higher prevalence of $E$. coli $(P<0.01)$. Samples which were collected in the summer season had the highest prevalence of bacteria (64.10\%). Significant difference was seen between the prevalence of EHEC and AEEC subtypes $(P<0.01)$. The most commonly detected virulence factors in both EHEC and AEEC subtypes were stx 1 and eae. The most commonly detected serogroups were $\mathrm{O} 26(43.75 \%)$ and $\mathrm{O} 157(25 \%)$ and there were no positive results for $0103,0145,091,0113$ and O128 serogroups. Aac (3)-IV (100\%), CITM (100\%) and tetA (62.50\%) were the most commonly detected antibiotic resistance genes. STEC strains harbored the highest levels of resistance against ampicillin (93.75\%), gentamycin (93. 75\%), tetracycline (87.50\%) and ciprofloxacin (81.25\%). All of the STEC strains were resistant to at least 3 antibiotics, while the prevalence of resistance against more than 12 antibiotics were $12.50 \%$.

Conclusions: High presence of $\mathrm{O} 157$ serogroups, EHEC strains and animal-based antibiotics in cooked foods showed insufficiency of cooking time and temperature in the kitchens of hospitals. Judicious prescription of antibiotics and attentions to the principles of food safety can reduce the risk of resistant and virulent strains of STEC in hospital foods.
\end{abstract}

Keywords: Shiga-toxin producing escherichia coli, Virulence factors, O-serogroups, Antibiotic resistance properties, Hospital foods, Iran

\footnotetext{
* Correspondence: Jonaidi2000@yahoo.com

${ }^{4}$ Health Research Center, Baqiyatallah University of Medical Sciences, Tehran,

Iran

Full list of author information is available at the end of the article
} 


\section{Background}

Access to adequate amounts of safe and healthy foods is key to supporting life and promoting good health of people. Insecure food containing pathogenic bacteria, viruses, parasites or harmful chemical elements, causes more than two-hundred diseases and disorders - ranging from diarrhea to cancers $[1,2]$. Foodborne diseases cause approximately 76 million illnesses, 325,000 hospitalizations, and 5,000 deaths in the United States each year [2-4]. Observation of basic principles of food hygiene can control and eliminate the distribution of foodborne diseases. Attention to the principles of food hygiene is more urgent especially in public places such as hospitals, restaurants, kindergartens, prisons, barracks, elderly care centers and asylums.

Using from regular, nutritious, safe and accurate food diet based on the characters of patients is one of the main aspects of treatment in hospitals. Due to the general weakness and suppression of the immune system of majority of patients in hospitals, hospitals foods should have good sanitary quality. Among all pathogenic agents causing food-borne diseases and food poisoning in hospitals, Escherichia coli (E. coli) had a had a significant importance [5-8].

E. coli is a gram-negative, non-sporulating, flagellated, rod-shaped and facultative anaerobic bacterium which belongs to Enterobacteriaceae family. Shiga (vero) toxin (Stx)-producing E. coli (STEC) is a subdivision of an important pathogenic group of this bacterium named enterohemorrhagic E. coli (EHEC) [9-11]. STEC strains are responsible for intensive clinical syndromes like lethal hemolytic uremic syndrome (HUS), bloody and non-bloody diarrhea, thrombotic thrombocytopenic purpura (TTP) and hemorrhagic colitis (HC) [9-11]. E. coli strains that cause $\mathrm{HC}$ and HUS in humans, express high levels of Shiga toxins (stx), cause attaching-effacing (A/E) lesions in intestinal epithelial cells, and possess a specific 60-MDa EHEC plasmid are known as EHEC [9-11]. One feature EHEC and Enteropathogenic E. coli (EPEC) have in common is the causation of intestinal epithelial lesions known as attaching and effacing (A/E). Attaching-effacing $E$ coli (AEEC) is a designation for those $E$. coli strains known to cause A/E lesions or at least carry the genes for this trait, and therefore include organisms that fall into either the EHEC or EPEC classes [9-11].

Outbreak of food poisoning, foodborne diseases, HUS, TTP and HC are associated with certain STEC O-serogroups mainly including O157, O26, O91, O103, O121, O113, O111, O145, O45 and O128 as well as untypeable groups [9-11]. Presence of latent virulence factors including Shiga toxins (stx1 and stx2), intimin (eaeA) and hemolysin $(h l y A)$ which are responsible for adhesion, colonization and invasion of bacterial cells into the intestinal walls is another factor for outbreak of foodborne diseases and disorders [9-11].

High levels of resistance in STEC strains is another important factor which increase the pathogenicity of bacteria. Unfortunately, STEC strains recovered from food stuffs and also cases of diarrhea and food poisoning harbored the high levels of resistance against commonly used groups of antibiotics including quinolones, aminoglycosides, macrolides, cephalosporins, sulfonamides, fluoroquinolones and tetracycline [9-15]. In the other hands, STEC strains of food poisoning show a high incidence of resistance (85-100\%) against commonly used antimicrobial agents $[9,10,12-14,16,17]$. Molecular epidemiological researches showed that presence of certain antibiotic resistance genes including the genes that encode resistance against fluoroquinolone ( $q n r)$, trimethoprim (dfrA1), cephalothin (blaSHV), tetracycline (tet $A$ and tet $B)$, ampicillin (CITM), gentamicin (aac (3)- IV), sulfonamide (sul1), chloramphenicol (cat1 and $c m l A)$, aminoglycosides $(\operatorname{aad} A 1)$, and erythromycin $(\operatorname{ere} A)$ is the most important reason for occurrence of antibiotic resistance in STEC strains [9-14, 16, 18].

According to the uncertain role of STEC strains in hospital foods and lack of epidemiological investigations in this field in Iran, the present research was carried out to study the distribution of virulence factors, Oserogroups, antibiotic resistance genes and antibiotic resistance pattern of STEC strains isolated from various types of raw and cooked hospital food samples.

\section{Methods}

\section{Samples and $E$. coli isolation}

From September 2013 to September 2014, a total of 580 various types of raw and cooked hospital foods including raw meat $(n=60)$, raw chicken $(n=60)$ and raw fish $(n=70)$ and cooked meat $(n=100)$, cooked chicken $(n=100)$, cooked fish $(n=110)$, and soup $(n=80)$ were randomly collected and immediately transferred to the Food Hygiene Research Center of the Islamic Azad University of Shahrekord in cooler with icepacks. Samples were collected from the various hospitals in Isfahan province, Iran. All food samples showed normal physical characters including odor, color and consolidation. All samples were collected through 4 different seasons of the year including summer $(n=120)$, autumn $(n=150)$, winter $(n=160)$ and spring $(n=150)$.

Totally, 10-g of crushed food samples were homogenized for $2 \mathrm{~min}$ in $90 \mathrm{ml}$ of Peptone Water (PW, Merck, Germany). Then the samples were cultured on 5\% sheep blood and MacConkey agar (Merck, Germany) and incubated for 18 to $24 \mathrm{~h}$ at $37^{\circ} \mathrm{C}$. Colonies with the typical color and appearance of $E$. coli were picked and streaked again on blood agar plates and re-streaked on EMB agar 
(Merck, Germany). All plates were further incubated for $24 \mathrm{~h}$ at $37^{\circ} \mathrm{C}$. The green metallic sheen colonies were considered as E. coli. The presumptive colonies were biochemically tested for growth on triple sugar iron agar (TSI) and lysine iron agar (LIA), oxidative/fermentative degradation of glucose, citrate utilization, urease production, indol fermentation, tryptophan degradation, glucose degradation (methyl red test) and motility.

\section{PCR confirmation of $E$. coli strains}

The colonies were further confirmed using the $16 \mathrm{~S}$ rRNA-based Polymerase Chain Reaction (PCR) based on the method previously described [19]. Bacterial strains were subcultured overnight in Luria-Bertani broth (Merck, Germany) and further incubated for $48 \mathrm{~h}$ at $37{ }^{\circ} \mathrm{C}$. Genomic DNA was extracted from bacterial colonies using the DNA extraction kit (Fermentas, Germany) according to manufacturer's instruction. The $10 \mathrm{ml}$ bacterial DNA extract and controls were amplified with $0.5 \mathrm{mM}$ primers (Forward: 5'-AGTTTGATCCTGGCTCAG-3' and Reverse: 5'-AGGCCCGGGAACGTATTCAC-3') (1343 bp) [19], $200 \mathrm{mM}$ of each dNTP (Fermentas, Germany), $2 \mathrm{mM} \mathrm{MgCl}$, $10 \mathrm{mM} \mathrm{KCl} \mathrm{PCR} \mathrm{buffer} \mathrm{and} \mathrm{1.0} \mathrm{U} \mathrm{Taq} \mathrm{polymerase}$ (Fermentas, Germany). The DNA was amplified in a programmable thermal cycler (Eppendorf, Mastercycler ${ }^{\circ}$ 5330, Eppendorf-Netheler-Hinz GmbH, Hamburg, Germany) PCR device using the following protocol: $94{ }^{\circ} \mathrm{C}$ for $5 \mathrm{~min}, 40$ cycles of $94{ }^{\circ} \mathrm{C}$ for $1 \mathrm{~min}, 55^{\circ} \mathrm{C}$ for $1 \mathrm{~min}$, $72{ }^{\circ} \mathrm{C}$ for $2 \mathrm{~min}$, and final $72{ }^{\circ} \mathrm{C}$ for $5 \mathrm{~min}$.

\section{PCR amplification of virulence factors, O-serogroups and antibiotic resistance genes}

Table 1 shows the list of primers as well as program and condition of each reaction used for detection of $\mathrm{O}$ serogroups, virulence genes and antimicrobial resistant genes $[11,20]$. Programmable DNA thermo-cycler (Eppendorf Flexrcycler ${ }^{2}$, Germany) was used in all PCR reactions. The PCR amplification products $(15 \mu \mathrm{l})$ were subjected to electrophoresis in a $1.5 \%$ agarose gel in $1 \times$ TBE buffer at $80 \mathrm{~V}$ for $30 \mathrm{~min}$, stained with SYBR Green (Fermentas, Germany). All runs included a negative DNA control consisting of PCR grade water and strains of E. coli O157:K88ac:H19, CAPM 5933 and E. coli O159:H20, CAPM 6006 were used as positive controls.

\section{Antimicrobial susceptibility testing}

Pattern of antimicrobial resistance was studied using the simple disk diffusion technique. The Mueller-Hinton agar (Merck, Germany) medium was used for this purpose. Antibiotic resistance of $E$. coli strains against 23 commonly used antibiotics was determined using the instruction of Clinical and Laboratory Standards Institute guidelines [21]. Susceptibility of E. coli strains were tested against tetracycline $(30 \mathrm{u}$ /disk), mezlocillin $(30 \mathrm{u} /$ disk), ampicillin (10 u/disk), cefotaxime (30 $\mu \mathrm{g} /$ disk), gentamycin $(10 \mu \mathrm{g} /$ disk), ciprofloxacin $(5 \mu \mathrm{g} /$ disk $)$, amikacin (30 u/disk), ceftazidime (30 $\mu \mathrm{g} /$ disk), imipenem (30 u/disk), cotrimoxazole (30 $\mu \mathrm{g} /$ disk), meropenem $(10 \mu \mathrm{g} /$ disk $)$, enrofloxacin $(5 \mu \mathrm{g} /$ disk), sulfamethoxazole (25 $\mathrm{\mu g} /$ disk), trimethoprim (5 $\mu \mathrm{g} /$ disk), levofloxacillin (5 $\mu \mathrm{g} /$ disk), cefipime $(30 \mu \mathrm{g} /$ disk $)$, streptomycin $(10 \mu \mathrm{g} /$ disk), polymyxin B (300 U/disk), vancomycine (5 $\mu \mathrm{g} /$ disk), and chloramphenicol ( $30 \mu \mathrm{g} /$ disk) antibiotic agents (Oxoid, UK). All of the inoculated plates were aerobically incubated at $37{ }^{\circ} \mathrm{C}$ for $18-24 \mathrm{~h}$ in an aerobic atmosphere. Results were interpreted based on the instruction provided by CLSI (2014) [21]. E. coli ATCC 25922 was used as quality control organisms in antimicrobial susceptibility determination.

\section{Statistical analysis}

Statistical analysis was performed using SPSS/16.0 software for significant relationships. The incidences of serogroups, virulence factors, O-serogroups and antibiotics resistance properties of $E$. coli isolated from various types of hospital food samples were statistically analyzed. Statistical significance was regarded at a $P$ value $<0.05$.

\section{Results}

Table 2 represents the total distribution of E. coli in various types of hospital food samples. Thirty-nine out of $580(6.72 \%)$ hospital food samples were contaminated with E. coli strains. Raw meat (20\%), raw chicken (16.66\%) and cooked meat (6\%) had the highest prevalence of $E$. coli. Statistically significant difference was seen for the prevalence of $E$. coli between raw and cooked hospital food samples $(P<0.01)$. Figure 1 shows the total distribution of $E$. coli strains in various seasons of the year based on the total numbers of $39 \mathrm{E}$. coli isolated. We found that hospital food samples of summer season had the highest prevalence of E. coli $(25 / 39$ : $64.10 \%)$, while those of winter had the lowest (3/39: $7.69 \%$ ). In the other hand, 25 out of 120 samples collected in summer (20.83\%), 5 out of 150 samples collected in autumn (3.33\%), 3 out of 160 samples collected in winter (1.87\%) and 6 out of 150 samples collected in spring (4\%) were positive for $E$. coli. Statistically significant difference was seen for the prevalence of $E$. coli between warm and cold season of the year $(P<0.05)$.

Table 3 represents the distribution of virulence factors in E. coli subtypes isolated from hospital food samples. Prevalence of EHEC and AEEC subtypes in the raw meat, raw chicken, cooked meat, cooked chicken, cooked fish and soup samples were $16.66 \%$ and $50 \%$, $20 \%$ and $60 \%, 25 \%$ and $50 \%, 0 \%$ and $33.33 \%, 0 \%$ and $50 \%$ and finally $33.33 \%$ and $66.66 \%$, respectively. All of the 
Table 1 The oligonucleotide primers and the PCR programs used for amplification of O-serogroups, virulence factors and antibiotic resistance genes of Escherichia coli isolates of hospital foods

\begin{tabular}{|c|c|c|c|c|}
\hline Target gene & Primer sequence $\left(5^{\prime}-3^{\prime}\right)$ & PCR product (bp) & PCR programs & PCR Volume $(50 \mu \mathrm{L})$ \\
\hline$\overline{0157}$ & $\begin{array}{l}\text { F: CGGACATCCATGTGATATGG } \\
\text { R: TTGCCTATGTACAGCTAATCC }\end{array}$ & 259 & \multirow{5}{*}{ 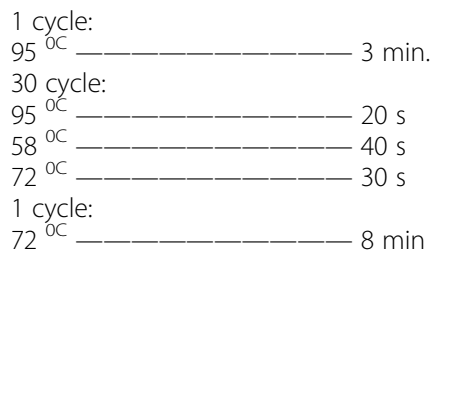 } & \multirow{5}{*}{$\begin{array}{l}5 \mu \mathrm{L} \text { PCR buffer 10× } \\
2 \mathrm{mM} \mathrm{MgCl} \\
150 \mu \mathrm{M} \text { dNTP (Fermentas) } \\
0.75 \mu \mathrm{M} \text { of each primers } \mathrm{F} \& \mathrm{R} \\
1.5 \cup \text { Taq DNA polymerase } \\
\text { (Fermentas) } \\
3 \mu \mathrm{L} \text { DNA template }\end{array}$} \\
\hline 0145 & $\begin{array}{l}\text { F: CCATCAACAGATTTAGGAGTG } \\
\text { R: TITCTACCGCGAATCTATC }\end{array}$ & 609 & & \\
\hline 0103 & $\begin{array}{l}\text { F: TTGGAGCGTTAACTGGACCT } \\
\text { R: GCTCCCGAGCACGTATAAG }\end{array}$ & 321 & & \\
\hline $\mathrm{O} 26$ & $\begin{array}{l}\text { F: CAGAATGGTTATGCTACTGT } \\
\text { R: CTTACATTTTITCGGCATC }\end{array}$ & 423 & & \\
\hline 0111 & $\begin{array}{l}\text { F: TAGAGAAATTATCAAGTTAGTTCC } \\
\text { R: ATAGTTATGAACATCTTGTTIAGC }\end{array}$ & 406 & & \\
\hline O91 & $\begin{array}{l}\text { F: GCTGACCTTCATGATCTGTTGA } \\
\text { R: TAATTTAACCCGTAGAATCGCTGC }\end{array}$ & 291 & \multirow{5}{*}{ 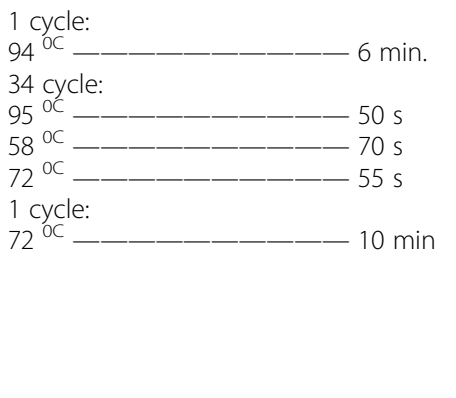 } & \multirow{5}{*}{$\begin{array}{l}5 \mu \mathrm{L} \text { PCR buffer 10x } \\
2 \mathrm{mM} \mathrm{Mgcl} \\
150 \mu \mathrm{M} \text { dNTP (Fermentas) } \\
0.75 \mu \mathrm{M} \text { of each primers } \mathrm{F} \& \mathrm{R} \\
1.5 \cup \text { Taq DNA polymerase } \\
\text { (Fermentas) } \\
3 \mu \mathrm{L} \text { DNA template }\end{array}$} \\
\hline 0128 & $\begin{array}{l}\text { F: GCTITCTGCCGATATTTGGC } \\
\text { R: CCGACGGACTGATGCCGGTGATT }\end{array}$ & 289 & & \\
\hline 0121 & $\begin{array}{l}\text { F: TGGCTAGTGGCATTCTGATG } \\
\text { R: TGATACTTAAGCCGCCCTTG }\end{array}$ & 322 & & \\
\hline 0113 & $\begin{array}{l}\text { F: GGGTTAGATGGAGCGCTATTGAGA } \\
\text { R: AGGTCACCCTCTGAATTATGGCAG }\end{array}$ & 771 & & \\
\hline $\mathrm{O} 45$ & $\begin{array}{l}\text { F: CCGGGTTCGATTTGTGAAGGTTG } \\
\text { R: CACAACAGCCACTACTAGGCAGAA }\end{array}$ & 527 & & \\
\hline stx 1 & $\begin{array}{l}\text { F: AAATCGCCATTCGTTGACTACTTCT } \\
\text { R: TGCCATTCTGGCAACTCGCGATGCA }\end{array}$ & 366 & \multirow{4}{*}{ 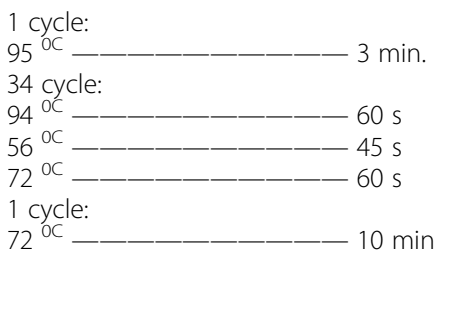 } & \multirow{4}{*}{$\begin{array}{l}5 \mu \mathrm{L} \text { PCR buffer } 10 \times \\
2 \mathrm{mM} \mathrm{MgCl} \\
150 \mu \mathrm{M} \text { dNTP (Fermentas) } \\
0.75 \mu \mathrm{M} \text { of each primers } \mathrm{F} \& \mathrm{R} \\
1.5 \cup \text { Taq DNA polymerase } \\
\text { (Fermentas) } \\
3 \mu \mathrm{L} \text { DNA template }\end{array}$} \\
\hline stx2 & $\begin{array}{l}\text { F: CGATCGTCACTCACTGGTTTCATCA } \\
\text { R: GGATATTCTCCCCACTCTGACACC }\end{array}$ & 282 & & \\
\hline eaeA & $\begin{array}{l}\text { F: TGCGGCACAACAGGCGGCGA } \\
\text { R: CGGTCGCCGCACCAGGATTC }\end{array}$ & 629 & & \\
\hline ehly & $\begin{array}{l}\text { F: CAATGCAGATGCAGATACCG } \\
\text { R: CAGAGATGTCGTTGCAGCAG }\end{array}$ & 432 & & \\
\hline $\operatorname{aadA1}$ & $\begin{array}{l}\text { F: TATCCAGCTAAGCGCGAACT } \\
\text { R: ATTTGCCGACTACCTTGGTC }\end{array}$ & 447 & \multirow{11}{*}{ 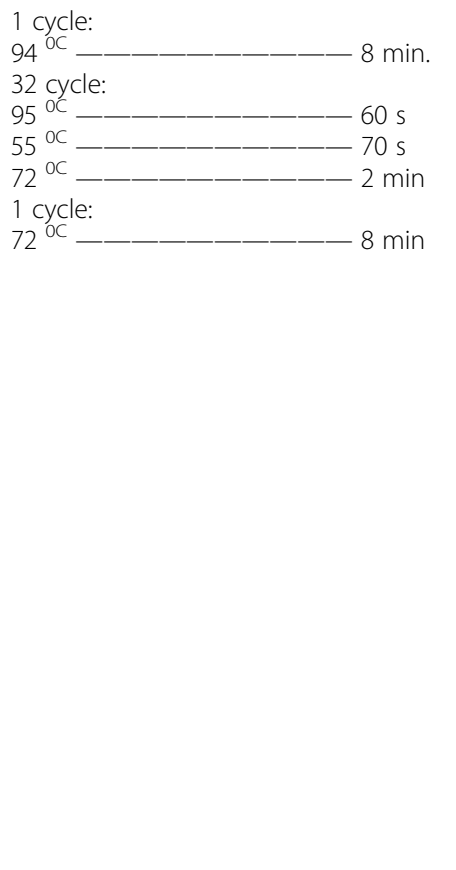 } & \multirow{11}{*}{$\begin{array}{l}5 \mu \mathrm{L} \text { PCR buffer } 10 \times \\
2 \mathrm{mM} \mathrm{MgCl} \\
150 \mu \mathrm{M} \text { dNTP (Fermentas) } \\
0.75 \mu \mathrm{M} \text { of each primers } \mathrm{F} \& \mathrm{R} \\
1.5 \cup \text { Taq DNA polymerase } \\
\text { (Fermentas) } \\
3 \mu \mathrm{L} \text { DNA template }\end{array}$} \\
\hline tetA & $\begin{array}{l}\text { F: GGTTCACTCGAACGACGTCA } \\
\text { R: CTGTCCGACAAGTTGCATGA }\end{array}$ & 577 & & \\
\hline tetB & $\begin{array}{l}\text { F: CCTCAGCTTCTCAACGCGTG } \\
\text { R: GCACCTTGCTGATGACTCTT }\end{array}$ & 634 & & \\
\hline dfrA1 & $\begin{array}{l}\text { F: GGAGTGCCAAAGGTGAACAGC } \\
\text { R: GAGGCGAAGTCTTGGGTAAAAAC }\end{array}$ & 367 & & \\
\hline qnr & $\begin{array}{l}\text { F: GGGTATGGATATTATTGATAAAG } \\
\text { R: CTAATCCGGCAGCACTATITA }\end{array}$ & 670 & & \\
\hline aac (3)-IV & $\begin{array}{l}\text { F: CTTCAGGATGGCAAGTTGGT } \\
\text { R: TCATCTCGTTCTCCGCTCAT }\end{array}$ & 286 & & \\
\hline sul1 & $\begin{array}{l}\text { F: TTCGGCATTCTGAATCTCAC } \\
\text { R: ATGATCTAACCCTCGGTCTC }\end{array}$ & 822 & & \\
\hline blaSHV & $\begin{array}{l}\text { F: TCGCCTGTGTATTATCTCCC } \\
\text { R: CGCAGATAAATCACCACAATG }\end{array}$ & 768 & & \\
\hline CITM & $\begin{array}{l}\text { F: TGGCCAGAACTGACAGGCAAA } \\
\text { R: TTTCTCCTGAACGTGGCTGGC }\end{array}$ & 462 & & \\
\hline cat1 & $\begin{array}{l}\text { F: AGTTGCTCAATGTACCTATAACC } \\
\text { R: TTGTAATTCATTAAGCATTCTGCC }\end{array}$ & 547 & & \\
\hline $\mathrm{cm} / \mathrm{A}$ & $\begin{array}{l}\text { F: CCGCCACGGTGTTGTTGTTATC } \\
\text { R: CACCTTGCCTGCCCATCATTAG }\end{array}$ & 698 & & \\
\hline
\end{tabular}


Table 2 Total prevalence of Escherichia coli in various types of hospital food samples

\begin{tabular}{llll}
\hline Types of samples & No. samples collected & No positive strains (\%) & PCR confirmation (\%) \\
\hline Raw meat & 60 & $12(20)$ & $12(20)$ \\
Raw chicken & 60 & $10(16.66)$ & $10(16.66)$ \\
Raw fish & 70 & $1(1.42)$ & $1(1.42)$ \\
Cooked meat & 100 & $6(6)$ & $6(6)$ \\
Cooked chicken & 100 & $3(3)$ & $3(3)$ \\
Cooked fish & 110 & $3(2.72)$ & $3(2.72)$ \\
Soup & 80 & $4(5)$ & $4(5)$ \\
Total & 580 & $39(6.72)$ & $39(6.72)$ \\
\hline
\end{tabular}

EHEC strains harbored all three stx 1 , eae and ehly genes together $(100 \%)$, while AEEC strains harbored variable percent of each gene. Statistically significant difference was seen between the prevalence of EHEC and AEEC subtypes $(P<0.01)$. We found that from a total of 39 E. coli strains isolated from samples, 16 strains (41.02\%) were positive for AEEC and EHEC subtypes which were considered as STEC strains. Raw fish samples had no positive strains for the EHEC and AEEC subtypes. EHEC strains which harbored all three stx1, eae and ehly genes together were considered as a O157 serogroup.

Table 4 shows the total distribution of O-serogroups in the STEC strains isolated from various types of hospital food samples. We found that O26 (43.75\%) and O157 (25\%) were the most commonly detected serogroups in the STEC strains of hospital food samples. There were no positive results for the O103, O145, O91, O113 and O128 serogroups. Statistically significant differences were seen for the prevalence of STEC O-serogroups between various types of samples $(P<0.05)$. Totally, raw chicken and soup samples harbored the most variable types of $\mathrm{O}$ serogroups.

Total distribution of antibiotic resistance genes in the STEC strains isolated from various types of hospital food samples is shown in Table 5. We found that aac (3)-IV (100\%), CITM (100\%), tetA (62.50\%), dfrA1 (56.25\%) and sul1 (56.25\%) were the most commonly detected antibiotic resistance genes. The less commonly detected antibiotic resistance genes were $\mathrm{cmlA}(12.50 \%)$, cat1 (25\%) and tetB (31.25\%). Statistically significant differences were seen for the prevalence of antibiotic resistance genes between various types of samples $(P<0.05)$.

Table 6 indicates the antibiotic resistance pattern of the STEC strains of various types of hospital food samples. STEC strains of our investigation harbored the highest levels of resistance against ampicillin (93.75\%), gentamycin $(93.75 \%)$, tetracycline $(87.50 \%)$, ciprofloxacin $(81.25 \%)$ and amikacin $(75 \%)$. Resistance of STEC strains of cooked samples against human-based antibiotics was entirely higher than animal-based antibiotics. Statistically significant differences were seen for the prevalence of antibiotic resistance between various types of samples $(P<0.05)$. Figure 2 represents the prevalence of multi-drug resistance in the STEC strains of hospital food samples. We found that all of the STEC strains of our investigation were resistant to at least 3 antibiotics, while prevalence of resistance against ten, eleven, twelve and more than twelve antibiotics were $37.50 \%, 25 \%, 18.75 \%$ and $12.50 \%$, respectively.

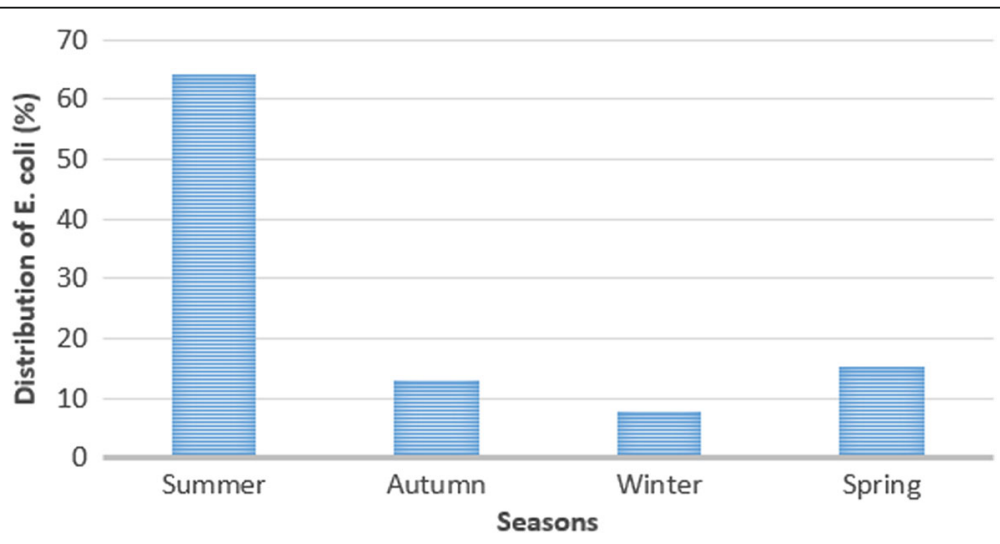

Fig. 1 Seasonal distribution of Escherichia coli in the hospital food samples 
Table 3 Distribution of virulence factors in Escherichia coli subtypes isolated from hospital food samples

\begin{tabular}{|c|c|c|c|}
\hline Samples (No. positive) & Subtypes & No. positive samples & Virulence genes \\
\hline \multirow[t]{4}{*}{ Raw meat (12) } & Non detected & $2(33.33)$ & - \\
\hline & EHEC & $1(16.66)$ & stx1, eae, ehly: 1 (100) \\
\hline & AEEC & $3(50)$ & $\begin{array}{l}\text { stx1: } 3 \text { (100) stx2: } 1 \text { (33.33) eaeA: } 3 \text { (100) stx1, eaeA: } 1 \text { (33.33) stx2, eaeA: } 1 \text { (33.33) } \\
\text { stx1, stx2, eaeA: } 1 \text { (33.33) }\end{array}$ \\
\hline & Total & $6(50)$ & \\
\hline \multirow[t]{4}{*}{ Raw chicken (10) } & Non detected & $1(20)$ & - \\
\hline & EHEC & $1(20)$ & stx1, eae, ehly: 1 (100) \\
\hline & AEEC & $3(60)$ & $\begin{array}{l}\text { stx1: } 3 \text { (100) stx2: } 1 \text { (33.33) eaeA: } 3 \text { (100) stx1, eaeA: } 1 \text { (33.33) stx2, eaeA: } 1 \text { (33.33) } \\
\text { stx1, stx2, eaeA: } 1 \text { (33.33) }\end{array}$ \\
\hline & Total & $5(50)$ & - \\
\hline \multirow[t]{4}{*}{ Raw fish (1) } & Non detected & $1(100)$ & - \\
\hline & EHEC & - & - \\
\hline & AEEC & - & stx1: - stx2: - eaeA: - stx1, eaeA: - stx2, eaeA: - stx1, stx2, eaeA: - \\
\hline & Total & $1(100)$ & - \\
\hline \multirow[t]{4}{*}{ Cooked meat (6) } & Non detected & $1(25)$ & - \\
\hline & EHEC & $1(25)$ & stx1, eae, ehly: 1 (100) \\
\hline & AEEC & $2(50)$ & $\begin{array}{l}\text { stx1: } 2 \text { (100) stx2: } 1 \text { (50) eaeA: } 2 \text { (100) stx1, eaeA: } 1 \text { (50) stx2, eaeA: } 1 \text { (50) stx1, } \\
\text { stx2, eaeA: } 1 \text { (50) }\end{array}$ \\
\hline & Total & $4(66.66)$ & - \\
\hline \multirow[t]{4}{*}{ Cooked chicken (3) } & Non detected & $1(33.33)$ & - \\
\hline & EHEC & - & - \\
\hline & AEEC & $1(33.33)$ & stx1: 1 (100) stx2: - eaeA: 1 (100) stx1, eaeA: 1 (100) stx2, eaeA: - stx1, stx2, eaeA: - \\
\hline & Total & $2(66.66)$ & - \\
\hline \multirow[t]{4}{*}{ Cooked fish (3) } & Non detected & $1(50)$ & - \\
\hline & EHEC & - & - \\
\hline & AEEC & $1(50)$ & stx1: 1 (100) stx2: - eaeA: 1 (100) stx1, eaeA: 1 (100) stx2, eaeA: - stx1, stx2, eaeA: - \\
\hline & Total & $2(66.66)$ & - \\
\hline \multirow[t]{4}{*}{ Soup (4) } & Non detected & - & - \\
\hline & EHEC & $1(33.33)$ & stx1, eae, ehly: 1 (100) \\
\hline & AEEC & $2(66.66)$ & $\begin{array}{l}\text { stx1: } 2 \text { (100) stx2: } 1 \text { (50) eaeA: } 2 \text { (100) stx1, eaeA: } 1 \text { (50) stx2, eaeA: } 1 \text { (50) stx1, } \\
\text { stx2, eaeA: } 1 \text { (50) }\end{array}$ \\
\hline & Total & $3(50)$ & - \\
\hline
\end{tabular}

\section{Discussion}

As far as we know the present investigation is the first prevalence report of the isolation of $E$. coli strains from raw and cocked hospital foods as well as molecular characterization and antimicrobial resistance properties of their STEC strains in the world. We found that $6.72 \%$ of hospital food samples were contaminated with E. coli strains and the prevalence of STEC strains were $41.02 \%$ which was considerable high. Gram-negative bacteria like $E$. coli are responsible for $30-70 \%$ of hospitalization in developed countries and E. coli was the most common etiologic gram-negative organism in the hospital environment [22, 23].

There were some probable reasons for the high prevalence of E. coli and also STEC strains in the hospital food samples. At first. high-volume food production and long process of catering caused several problems such as lack of adequate precision and accuracy in the preparation and washing of raw materials and even their well cooking, lack of enough time and even temperature for cooking of raw materials, cooling of foods during processing, lack of reaching of sufficient heat to the center of meat and other food materials, lack of enough time to withdraw meat from the frozen state and finally cooking of meat and its products more than the daily requirement and then their storage at improper temperature and conditions. These mentioned circumstances maybe lead to survival and even growth of pathogenic microorganisms in food stuffs. At second, using from unsanitary and also contaminated equipment and dishes for production of 
Table 4 Total distribution of O-serogroups in the Shiga toxigenic Escherichia coli strains isolated from various types of hospital food samples

\begin{tabular}{|c|c|c|c|c|c|c|c|c|c|c|}
\hline \multirow{2}{*}{$\begin{array}{l}\text { Samples (No. STEC } \\
\text { strains) }\end{array}$} & \multicolumn{10}{|c|}{ Distribution of O-serogroups (\%) } \\
\hline & O157 & $\mathrm{O} 26$ & 0103 & $\mathrm{O} 111$ & O145 & $\mathrm{O} 45$ & O91 & 0113 & 0121 & 0128 \\
\hline Raw meat (4) & $1(25)$ & $2(50)$ & - & $1(25)$ & - & - & - & - & - & - \\
\hline Raw chicken (4) & $1(25)$ & $1(25)$ & - & $1(25)$ & - & - & - & - & $1(25)$ & - \\
\hline Cooked meat (3) & $1(33.33)$ & $1(33.33)$ & - & - & - & $1(33.33)$ & - & - & - & - \\
\hline Cooked chicken (1) & - & $1(100)$ & - & - & - & - & - & - & - & - \\
\hline Cooked fish (1) & - & $1(100)$ & - & - & - & - & - & - & - & - \\
\hline Soup (3) & $1(33.33)$ & $1(33.33)$ & - & - & - & - & - & - & 1 (33.33) & - \\
\hline Total (16) & $4(25)$ & $7(43.75)$ & - & $2(12.50)$ & - & $1(6.25)$ & - & - & $2(12.50)$ & - \\
\hline
\end{tabular}

foods in hospitals. At third, presence of nurses and servants, which maybe the sources of dangerous pathogenic agents, in the distribution of food to patients. Prevalence of E. coli in raw and cooked fish samples were $1.42 \%$ and $2.72 \%$, respectively. Presence of powerful competitor microflora in raw fish and also their destruction and addition of E. coli strains derived from contaminated staffs of the hospital's kitchen are two main reasons for above findings. Because the large numbers of $E$. coli isolates recovered from raw meat, proper preparation of the raw meat can eliminate the distribution of bacteria. Unfortunately, basic principles of meat inspections were not observed in Iranian slaughterhouses. Therefore, close contact of animal carcasses with each other and even slaughterhouse floor, blood, content of the digestive tract and wool and skin of slaughtered animal caused transmission and distribution of pathogenic agents like $E$. coli to meat of slaughtered animals. Besides, the role of possible colonizers such as meat inspectors, butchers and miscellaneous people which mainly have come into the slaughterhouse for buying of meat and finally animals like rats, cats and birds which have been entered from outside the slaughterhouse as a sources of pathogenic E. coli should not be overlooked. Survival of STEC strains of raw food samples even after cooking procedure and occurrence of cross contamination after cooking procedure are two important routes of hospital foods contamination.
We found marked seasonality in distribution of $E$. coli strains in hospital food samples. High incidence of $E$. coli strains in summer season $(64.10 \%)$ could be related to the low levels of individual hygiene in this season. The higher prevalence of STEC strains may be related to higher growth of them in hot seasons of the year. Of studies that have been conducted in this field [24-26], all have shown a seasonal distribution for $E$. coli with a higher prevalence of strains in warmer months of the year [24-26].

The results of the current study showed that resistant and virulence STEC strains had the high prevalence in the hospital food samples. Limit studies have been conducted in this field. Ifeadike et al., [27] revealed that the prevalence of $E$. coli strains in food handlers of Nigerian hospitals were $1.8 \%$ which was lower than our findings in hospital foods. They concluded that poor and faulty food-handling practices have been identified as the leading cause of the majority of food-borne disease in hospitals. Ha et al., [7] in a research which was conducted in order to study the contamination rate of raw foods in schools, factories, and hospitals of Vietnam reported that the prevalence of $E$. coli in raw poultry, meat, fish and vegetable samples were $45,21.3,6.6$ and $18.5 \%$, respectively which all were higher than our results.

STEC strains of our investigation harbored resistance against multiple antibiotics. The results of disk diffusion

Table 5 Total distribution of antibiotic resistance genes in the Shiga toxigenic Escherichia coli strains isolated from various types of hospital food samples

\begin{tabular}{|c|c|c|c|c|c|c|c|c|c|c|c|}
\hline \multirow{2}{*}{$\begin{array}{l}\text { Samples (No. STEC } \\
\text { strains) }\end{array}$} & \multicolumn{11}{|c|}{ Distribution of antibiotic resistance genes (\%) } \\
\hline & $\operatorname{aadA1}$ & tetA & tetB & dfrA1 & qnr & aac (3)-IV & sul1 & blaSHV & CITM & cat1 & $\mathrm{cmlA}$ \\
\hline Raw meat (4) & $1(25)$ & $1(25)$ & - & $1(25)$ & $1(25)$ & $4(100)$ & $2(50)$ & $1(25)$ & $4(100)$ & $1(25)$ & - \\
\hline Raw chicken (4) & $2(50)$ & $2(50)$ & $1(25)$ & $2(50)$ & $1(25)$ & $4(100)$ & $4(100)$ & $2(50)$ & $4(100)$ & $3(75)$ & $2(50)$ \\
\hline Cooked meat (3) & $1(33.33)$ & $3(100)$ & $2(66.66)$ & $2(66.66)$ & $2(66.66)$ & $3(100)$ & $1(33.33)$ & $1(33.33)$ & $3(100)$ & - & - \\
\hline Cooked chicken (1) & - & $1(100)$ & $1(100)$ & $1(100)$ & $1(100)$ & $1(100)$ & $1(100)$ & - & $1(100)$ & - & - \\
\hline Cooked fish (1) & - & $1(100)$ & - & $1(100)$ & - & $1(100)$ & - & - & $1(100)$ & - & - \\
\hline Soup (3) & $1(33.33)$ & $2(66.66)$ & $1(33.33)$ & $2(66.66)$ & $1(33.33)$ & $3(100)$ & $1(33.33)$ & $1(33.33)$ & $3(100)$ & - & - \\
\hline Total (16) & $5(31.25)$ & $10(62.50)$ & $5(31.25)$ & $9(56.25)$ & $6(37.50)$ & $16(100)$ & $9(56.25)$ & $5(31.25)$ & $16(100)$ & $4(25)$ & $2(12.50)$ \\
\hline
\end{tabular}


Table 6 Antibiotic resistance pattern of Shiga toxigenic Escherichia coli strains isolated from various types of hospital food samples

\begin{tabular}{|c|c|c|c|c|c|c|c|}
\hline \multirow{2}{*}{$\begin{array}{l}\text { Antibiotic } \\
\text { resistance }\end{array}$} & \multicolumn{6}{|c|}{ Samples (No. STEC strains) } & \multirow[b]{2}{*}{ Total (16) } \\
\hline & Raw meat (4) & Raw chicken (4) & Cooked meat (3) & Cooked chicken (1) & Cooked fish (1) & Soup (3) & \\
\hline Tetracycline & $4(100)$ & $4(100)$ & $2(66.66)$ & $1(100)$ & $1(100)$ & $2(66.66)$ & $14(87.50)$ \\
\hline Ampicillin & $4(100)$ & $4(100)$ & $3(100)$ & $1(100)$ & $1(100)$ & $2(66.66)$ & $15(93.75)$ \\
\hline Gentamycin & $4(100)$ & $4(100)$ & $2(66.66)$ & $1(100)$ & $1(100)$ & $3(100)$ & $15(93.75)$ \\
\hline Amikacin & $2(50)$ & $3(75)$ & $2(66.66)$ & $1(100)$ & $1(100)$ & $3(100)$ & $12(75)$ \\
\hline Imipenem & - & - & - & $1(100)$ & - & $1(33.33)$ & $2(12.5)$ \\
\hline Meropenem & - & - & - & - & - & $1(33.33)$ & $1(6.25)$ \\
\hline Mezlocillin & - & - & $1(33.33)$ & $1(100)$ & $1(100)$ & $1(33.33)$ & $4(25)$ \\
\hline Sulfamethoxazole & $1(25)$ & $3(75)$ & $1(33.33)$ & $1(100)$ & $1(100)$ & $2(66.66)$ & $9(56.25)$ \\
\hline Cefotaxime & - & - & - & $1(100)$ & - & $2(66.66)$ & $3(18.75)$ \\
\hline Ciprofloxacin & $2(50)$ & $3(75)$ & $3(100)$ & $1(100)$ & $1(100)$ & $3(100)$ & $13(81.25)$ \\
\hline Enrofloxacin & $2(50)$ & $4(100)$ & - & - & - & 1 (33.33) & $7(43.75)$ \\
\hline Cotrimoxazole & - & - & $2(66.66)$ & $1(100)$ & $1(100)$ & $2(66.66)$ & $6(37.50)$ \\
\hline Ceftazidime & - & - & $1(33.33)$ & $1(100)$ & $1(100)$ & $2(66.66)$ & $5(31.25)$ \\
\hline Trimethoprim & $1(25)$ & $2(50)$ & $2(66.66)$ & $1(100)$ & $1(100)$ & $1(33.33)$ & $8(50)$ \\
\hline Cefipime & - & - & $2(66.66)$ & $1(100)$ & $1(100)$ & $2(66.66)$ & $6(37.50)$ \\
\hline Levofloxacillin & - & - & $2(66.66)$ & $1(100)$ & $1(100)$ & $3(100)$ & $7(43.75)$ \\
\hline Streptomycin & $1(25)$ & $2(50)$ & - & - & - & - & $3(18.75)$ \\
\hline Vancomycine & - & - & $1(33.33)$ & $1(100)$ & $1(100)$ & $2(66.66)$ & $5(31.25)$ \\
\hline Polymyxin B & - & - & $1(33.33)$ & $1(100)$ & $1(100)$ & $1(33.33)$ & $4(25)$ \\
\hline Chloramphenicol & $1(25)$ & $2(50)$ & - & - & - & - & $3(18.75)$ \\
\hline
\end{tabular}

method obtained from STEC strains of our investigation were also confirmed by the presence of specific antibiotic resistance genes encode resistance against determined antibiotics. Stewardson et al., [5] reported that 92\% of all food samples which were collected from hospitals in Switzerland were positive for Extended-Spectrum-Beta-lactamase-producing-Enterobacteriaceae (ESBL-PE). ESBL-producing $E$. coli was the most commonly detected (44.77\%). They showed $6.45 \%$ of eligible food handlers were positive for
ESBL-PE and prevalence of $E$. coli strains among ESBL-PE strains were $83.33 \%$. ESBL-PE strains were generally not multidrug resistant, with $100,90,87,79$, and $98 \%$ of strains susceptible to meropenem, gentamicin, ciprofloxacin, cotrimoxazole, and fosfomycin, respectively. Antibiotic resistance-based finding of Stewardson et al., [5] study was in contrast with our results which showed the high prevalence of resistance and also antibiotic resistance genes. This part of our study was similar

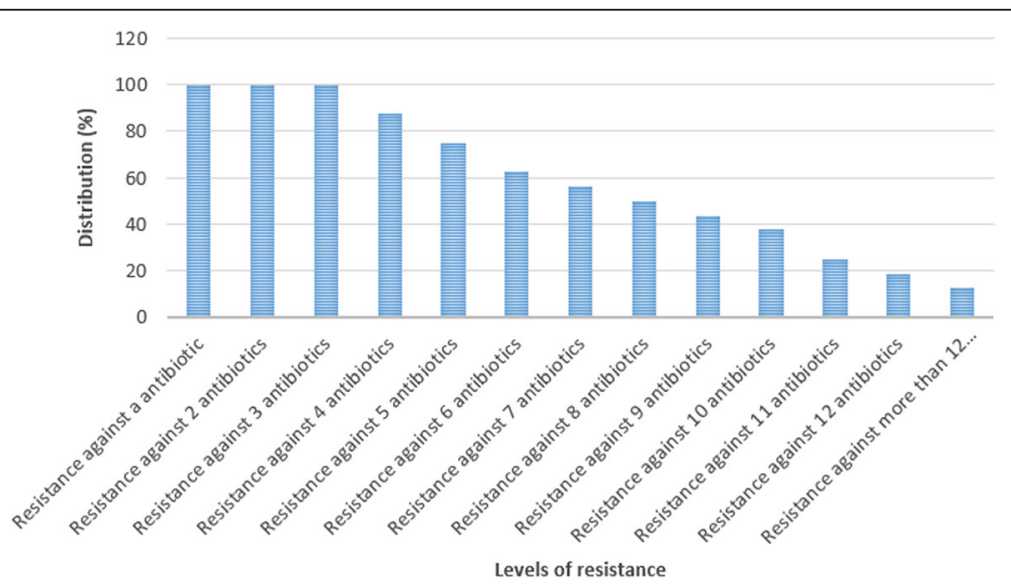

Fig. 2 Prevalence of multi-drug resistant strains of Shiga toxigenic Escherichia coli isolated from hospital food samples 
with those of India [28] (high prevalence of resistance against erythromycin, cephalothin, amikacin, kanamycin and gentamicin antibiotics), South Africa [29] (high presence of CITM, blaSHV and tetA antibiotic resistance genes), Korea [30] (high prevalence of resistance against ampicillin, tetracycline, streptomycin and amikacin antibiotics) and Mexico [31] (high presence of tet, blaSHV, qnr and aac (3)-IV antibiotic resistance genes and also high prevalence of resistance against ampicillin, trimethoprim-sulfamethoxazole, chloramphenicol and cephalotine antibiotics). Momtaz et al., [20] reported that aac (3)-IV (68.03\%), sul1 (82.78\%), blaSHV (56.55\%), aadA1 $(60.65 \%)$ and tetA $(51.63 \%)$ and also resistance against tetracycline $(86.88 \%)$, penicillin $(100 \%)$, gentamycin $(62.29 \%)$ and streptomycin $(54.91 \%)$ were the most commonly reported antibiotic resistance-based finding of STEC strains of diarrheic patients which was similar to our results.

STEC strains of hospital food samples and especially cooked samples harbored the high levels of resistance against human-based antibiotics such as meropenem, levofloxacillin, mezlocillin, cefipime, polymyxin B, cefotaxime, ciprofloxacin, cotrimoxazole, ceftazidime and imipenem which can indirectly confirm their anthropogenic origin of these strains. The prevalence of antibiotic resistance genes and especially those that were encode resistance against human-based antibiotics were also high among STEC strains recovered from cooked hospital food samples which also can indirectly approved the transmission of anthropogenic STEC strains probably from staffs of hospital kitchens to foods after cooking process. Prevalence of resistance against chloramphenicol antibiotic in the STEC strains of meat and chicken samples of our investigation were 25 and 50\%, respectively. There were no positive results in other raw and also all of the cooked food samples. The Iranian Food and Drug Administration (FDA) listed chloramphenicol as a forbidden antibiotic for treatment of diseases of animals and poultries. It is because of prescription of this antibiotic may cause dangerous effects on animals and even humans who use from their edible sources like meat and milk. The presence of high chloramphenicol resistance showed its irregular and unauthorized use in veterinary treatment and especially field of poultry in Iran. Veterinary practitioners of the field of poultry use from this antibiotic as a primary choice for treatment of diseases. Therefore, in a very short period of time, antibiotic resistance appears. Similar results have been reported by Momtaz and Jamshidi [32], Ranjbar et al., [33] and Colello et al., [34]. Momtaz and Jamshidi [32] reported that $73.17 \%$ of STEC strains recovered from poultry meat samples were resistant against chloramphenicol which was higher than our findings. Ranjbar et al., [33] found that the prevalence of resistance against chloramphenicol in the STEC strains recovered from various types of food samples were $21.95 \%$ which was considerable. Colello et al. [34] showed that majority of STEC strains in the Argentina harboured the gene that encodes resistance against chloramphenicol.

The most commonly detected serogroups in the STEC strains of hospital food samples of our study were O26 and O157. Presence of O157 serogroup showed that some of our strains had animal-based origin. O157 serogroup is predominant in foods with animal origin. STEC strains of raw foods with animal origins like those of meat and chicken were remained even after cooking of foods. Presence of this serogroup. High prevalence of O157 and O26 serogroups have been reported previously from Iran (Hemmatinezhad et al., [35]), Nigeria (Mamza et al., [36]), Canada (Neher et al., [37]) and Turkey (Avaz et al., [38]). Dehkordi et al., [11] reported similar profile for distribution of STEC O-serogroups. They showed that total prevalence of O157, O145, O128, O121, O113, O111, O103, O91, O45 and O26 serogroups in the STEC strains of food stuffs were $26,6,8,4,6,6,6,4,4$ and $12 \%$, respectively, which was similar to our findings.

Another part of our investigation focused on the distribution of stx 1, stx2, eaeA and ehly virulence factors in the $E$. coli strains of hospital foods. High presence of these factors in EHEC and AEEC subtypes showed their high pathogenicity for human and especially patients. Simultaneous presence of stx 1 and eaeA and stx 2 and $e a e A$ virulence factors in some strains of $E$. coli of hospital foods indicated the important public health problem facing Iranian hospitals and health centers which can attributed to occurrence of dangerous food poisoning and STEC-based food-borne diseases in hospitals. Simultaneous presence of stx 1 and eaeA and stx 2 and $e a e A$ virulence factors have been reported previously [39-41]. In a study which was conducted by Momtaz et al., [42] the prevalence of EHEC and AEEC subtypes in E. coli strains of food samples were 15.06 and $49.31 \%$, respectively. They showed that all of the EHEC strains were positive for all stx 1, eaeA and ehly virulence genes, while the prevalence of these genes in AEEC subtypes were 77.77, 13.88 and $55.55 \%$, respectively. Higher prevalence of AEEC subtypes was also reported by various investigations $[9-11,20,32,33]$. Prevalence of AEEC subtypes in the studies of Momtaz et al., [9] and Dehkordi et al., [11] were 79.41 and $62 \%$, respectively which were higher than EHEC subtype in both studies. Momtaz et al., [10] reported that the prevalence of AEEC subtypes in the E. coli strains recovered from the meat samples of beef, sheep, goat and camel species were 45.54, 44.87, 39.02 and $50.00 \%$, respectively which were higher than those of EHEC. Momtaz et al., [20] reported that the prevalence of AEEC subtypes among the E. coli strains of Iranian diarrheic patients had a range of 47 to $75 \%$ which was entirely high. 


\section{Conclusions}

In conclusions, we identified a large number of $\mathrm{O}$ serogroups, virulence factors, antibiotic resistance genes and pattern of antibiotic resistance in STEC strains recovered from hospital foods. Raw meat, raw chicken and cooked meat, summer season, stx 1 and eaeA virulence factors, AEEC subtype, O26 and O157 serogroups, aac (3)-IV, CITM, tetA, dfrA1) and sul1 antibiotic resistance genes, resistance against ampicillin, gentamycin, tetracycline, ciprofloxacin and amikacin and presence of multi-drug resistant strains were the most commonly detected characters in the STEC strains of hospital foods. Presence of O157 serogroups, EHEC strains, animal-based antibiotics and even antibiotic resistance genes which encode resistance against animal-based antibiotics in cooked foods showed insufficiency of cooking time and temperature in the kitchens of hospitals. It seems that there were no strict supervisions on the principles of food hygiene in Iranian hospitals. Due to the low levels of STEC resistance against imipenem, meropenem, streptomycin and cefotaxim antibiotics, occurrence of food poisonings due to the STEC strains in tested Iranian hospitals can be treated with their regular prescription. Attentions to the results of disk diffusion method and principles of hazard analysis and critical control point (HACCP) system can reduce the risk of STEC strains in hospital food stuffs.

\section{Abbreviations}

AEEC: Attaching and effacing E. coli; E. coli: Escherichia coli; Eae: Intimin; EHEC: Enterohemolysin or Enterohaemorrhagic Escherichia coli; Ehly: Hemolysin; HC: Hemorrhagic Colitis; HUS: Hemolytic Uremic Syndrome; PCR: Polymerase Chain Reaction; SPSS: Statistical Package for the Social Sciences; STEC: Shiga toxin producing Escherichia coli; Stx: Shiga toxin

\section{Acknowledgements}

The authors would like to thank Prof. Hassan Momtaz at the Department of Microbiology, Islamic Azad University of Shahrekord, Shahrekord Iran and Prof. Afshin Akhondzadeh Basti and Prof. Ali Misaghi at the Department of Food Hygiene and Quality Control, University of Tehran, Tehran, Iran for their important technical support.

\section{Funding}

This work was supported by the Baqiyatallah University of Medical Sciences, Tehran, Iran (grant no. 94/5050).

\section{Availability of data and material}

None.

\section{Authors' contributions}

RR and MM contributed to study design, culture-based identification, disk diffusion and PCR genetic alignments. ER and MM carried out on samples collection, statistical analysis and DNA extraction. NJJ and FSD wrote and drafted the manuscript. All authors road and approved the final manuscript.

\section{Competing interests}

The authors declare that they have no competing interests

\section{Consent for publication}

There was no consent for publication.

\section{Ethics approval and consent to participate}

Ethical Committee of Research of the Baqiyatallah University of Medical Sciences, Tehran, Iran (Consent Ref Number 94-11052). Verification of this research project and the licenses related to sampling process were approved by Prof. Reza Ranjbar (Approval Ref Number Med-94-206350).

\section{Author details}

${ }^{1}$ Molecular Biology Research Center, Baqiyatallah University of Medical Sciences, Tehran, Iran. ${ }^{2}$ Doctor Veterinary Medicine, College of Veterinary Medicine, Islamic Azad University, Shahrekord Branch, Shahrekord, Iran. ${ }^{3}$ Young Researchers and Elites Club, Shahrekord Branch, Islamic Azad University, Shahrekord, Iran. ${ }^{4}$ Health Research Center, Baqiyatallah University of Medical Sciences, Tehran, Iran. ${ }^{5}$ Department of Food Hygiene and Public Health, College of Veterinary Medicine, Shahrekord Branch, Shahrekord, Iran.

Received: 9 November 2016 Accepted: 16 December 2016

Published online: 07 January 2017

\section{References}

1. Gould LH, Walsh KA, Vieira AR, Herman K, Williams IT, Hall AJ, Cole D. Surveillance for foodborne disease outbreaks-United States, 1998-2008. MMWR Surveill Summ. 2013:62:1-34.

2. Havelaar AH, Kirk MD, Torgerson PR, Gibb HJ, Hald T, Lake RJ, Praet N, Bellinger DC, De Silva NR, Gargouri N. World Health Organization Global estimates and regional comparisons of the burden of foodborne disease in 2010. PLoS Med. 2015:12:e1001923.

3. Control CD. Prevention. Surveillance for Foodborne Disease Outbreaks, United States, 2013, Annual Report. Atlanta: US Department of Health and Human Services; 2014

4. Scallan E, Hoekstra RM, Angulo FJ, Tauxe RV, Widdowson M-A, Roy SL, Jones $J \mathrm{~L}$, Griffin PM. Foodborne illness acquired in the United States-major pathogens. Emerg Infect Dis. 2011;17:7-15.

5. Stewardson AJ, Renzi G, Maury N, Vaudaux C, Brassier C, Fritsch E, Pittet D, Heck M, van der Zwaluw K, Reuland EA. Extended-Spectrum $\beta$-LactamaseProducing Enterobacteriaceae in Hospital Food: A Risk Assessment. Infect Control Hosp Epidemiol. 2014;35:375-83.

6. Luo Y, Cui S, Li J, Yang J, Lin L, Hu C, Jin S, Ye L, Zhao Q, Ma Y. Characterization of Escherichia coli isolates from healthy food handlers in hospital. Microb Drug Resist. 2011;17:443-8.

7. Anvarinejad M, Farshad SH, Ranjbar R, Giammanco GM, Alborzi A, Japoni A. Genotypic analysis of E. coli strains isolated from patients with cystitis and pyelonephritis. Iran Red Crescent Med J. 2012;14:408-16.

8. Cooke EM, Kumar P, Shooter R, Rousseau S, Foulkes A. Hospital food as a possible source of Escherichia coli in patients. Lancet. 1970;295:436-7.

9. Momtaz H, Farzan R, Rahimi E, Safarpoor Dehkordi F, Souod N. Molecular characterization of Shiga toxin-producing Escherichia coli isolated from ruminant and donkey raw milk samples and traditional dairy products in Iran. Sci World J. 2012:2012:231342.

10. Momtaz H, Dehkordi FS, Rahimi E, Ezadi H, Arab R. Incidence of Shiga toxinproducing Escherichia coli serogroups in ruminant's meat. Meat Sci. 2013;95:381-8.

11. Dehkordi FS, Yazdani F, Mozafari J, Valizadeh Y. Virulence factors, serogroups and antimicrobial resistance properties of Escherichia coli strains in fermented dairy products. BMC Res Notes. 2014;7:1.

12. Tajbakhsh E, Khamesipour F, Ranjbar R, Ugwu IC. Prevalence of class 1 and 2 integrons in multi-drug resistant Escherichia coli isolated from aquaculture water in Chaharmahal Va Bakhtiari province, Iran. Ann Clin Microbiol Antimicrob. 2015;14:37.

13. Ranjbar R, Karami A, Farshad S, Giammanco GM, Mammina C. Typing methods used in the molecular epidemiology of microbial pathogens: a how-to guide. New Microbiol. 2014;37:1-15.

14. Wang J, Stanford K, McAllister TA, Johnson RP, Chen J, Hou H, Zhang G, Niu YD. Biofilm Formation, Virulence Gene Profiles, and Antimicrobial Resistance of Nine Serogroups of Non-0157 Shiga Toxin-Producing Escherichia coli. Foodborne Pathog Dis. 2016;13:316-24.

15. Farshad S, Ranijbar R, Japoni A, Hosseini M, Anvarinejad M, Mohammadzadegan R. Microbial susceptibility, virulence factors, and plasmid profiles of uropathogenic Escherichia coli strains isolated from children in Jahrom, Iran. Arch Iran Med. 2012:15:312-6.

16. Ranjbar, R, Haghi-Ashtiani, MT, Jafari, NJ, Abedini, M. The prevalence and antimicrobial susceptibility of bacterial uropathogens isolated from pediatric patients. Iran J Publ Health. 2009;38:134-138. 
17. Abdi S, Ranjbar R, Vala MH, Jonaidi N, Bejestany OB, Bejestany FB. Frequency of bla TEM, bla SHV, bla CTX-M, and gnrA Among Escherichia coli Isolated From Urinary Tract Infection. Arch Clin Infect Dis. 2014;9:e18690.

18. Momtaz H, Karimian A, Madani M, Dehkordi FS, Ranjbar R, Sarshar M, Souod N. Uropathogenic Escherichia coli in Iran: serogroup distributions, virulence factors and antimicrobial resistance properties. Ann Clin Microbiol Antimicrob. 2013;12:1

19. Woo PC, Cheung EY, K-w L, K-y Y. Identification by 165 ribosomal RNA gene sequencing of an Enterobacteriaceae species with ambiguous biochemical profile from a renal transplant recipient. Diagn Microbiol Infect Dis. 2001;39:85-93.

20. Momtaz H, Dehkordi FS, Hosseini MJ, Sarshar M, Heidari M. Serogroups, virulence genes and antibiotic resistance in Shiga toxin-producing Escherichia coli isolated from diarrheic and non-diarrheic pediatric patients in Iran. Gut Pathog. 2013;5:1.

21. Wayne P. Clinical and Laboratory Standards Institute (CLSI). Performance standards for antimicrobial susceptibility testing. Twenty-second informational supplement M100-S21. United States, Wayne. 2012

22. Hidron Al, Edwards JR, Patel J, Horan TC, Sievert DM, Pollock DA, Fridkin SK. Antimicrobial-resistant pathogens associated with healthcare-associated infections: annual summary of data reported to the National Healthcare Safety Network at the Centers for Disease Control and Prevention, 2006-2007. Infect Control Hosp Epidemiol. 2008;29:996-1011.

23. Peleg AY, Hooper DC. Hospital-acquired infections due to gram-negative bacteria. N Engl J Med. 2010;362:1804-13.

24. Alam M, Zurek L. Seasonal prevalence of Escherichia coli O157: H7 in beef cattle feces. J Food Prot. 2006;69:3018-20.

25. Barkocy-Gallagher GA, Arthur TM, Rivera-Betancourt M, Nou X, Shackelford SD, Wheeler TL, Koohmaraie M. Seasonal prevalence of Shiga toxin-producing Escherichia coli, including O157: H7 and non-O157 serotypes, and Salmonella in commercial beef processing plants. J Food Prot 2003;66:1978-86.

26. Williams MS, Withee JL, Ebel ED, Bauer Jr NE, Schlosser WD, Disney WT, Smith DR, Moxley RA. Determining relationships between the seasonal occurrence of Escherichia coli 0157: H7 in live cattle, ground beef, and humans. Foodborne Pathog Dis. 2010;7:1247-54.

27. Ifeadike C, Ironkwe O, Adogu P, Nnebue C, Emelumadu O, Nwabueze S, Ubajaka C. Prevalence and pattern of bacteria and intestinal parasites among food handlers in the Federal Capital Territory of Nigeria. Niger Med J. 2012;53:166-71.

28. Mahanti A, Samanta I, Bandopaddhay S, Joardar SN, Dutta TK, Batabyal S, Sar TK, Isore DP. Isolation, molecular characterization and antibiotic resistance of Shiga Toxin-Producing Escherichia coli (STEC) from buffalo in India. Lett Appl Microbiol. 2013;56:291-8.

29. Iweriebor BC, Iwu CJ, Obi LC, Nwodo UU, Okoh Al. Multiple antibiotic resistances among Shiga toxin producing Escherichia coli 0157 in feces of dairy cattle farms in Eastern Cape of South Africa. BMC Microbiol. 2015;15:213.

30. Kang E, Hwang SY, Kwon KH, Kim KY, Kim JH, Park YH. Prevalence and characteristics of Shiga toxin-producing Escherichia coli (STEC) from cattle in Korea between 2010 and 2011. J Vet Sci. 2014;15:369-79.

31. Castillo FYR, González FJA, Garneau P, Díaz FM, Barrera ALG, Harel J. Presence of multi-drug resistant pathogenic Escherichia coli in the San Pedro River located in the State of Aguascalientes, Mexico. Front Microbiol. 2013:4:147.

32. Momtaz H, Jamshidi A. Shiga toxin-producing Escherichia coli isolated from chicken meat in Iran: Serogroups, virulence factors, and antimicrobial resistance properties. Poult Sci. 2013;92:1305-13.

33. Ranjbar R, Sheikhshahrokh A, Jonaidi Jafari N. Shiga (vero) toxin producing Escherichia coli in various types of food stuffs; virulence factors, O-serogroups and antimicrobial resistance properties. J food Safety. 2016;1-12.

34. Colello R, Etcheverría Al, Conza JAD, Gutkind GO, Padola NL. Antibiotic resistance and integrons in Shiga toxin-producing Escherichia coli (STEC). Braz J Microbiol. 2015;46:1-5.

35. Hemmatinezhad B, Khamesipour F, Mohammadi M, Safarpoor Dehkordi F, Mashak Z. Microbiological Investigation of O-Serogroups, Virulence Factors and Antimicrobial Resistance Properties of Shiga Toxin-Producing Escherichia Coli Isolated from Ostrich, Turkey and Quail Meats. J Food Saf. 2015;35:491-500.

36. Mamza SA, Egwu GO, Mshelia GD. Antibiotic susceptibility patterns of beta-lactamase-producing Escherichia coli and Staphylococcus aureus isolated from chickens in Maiduguri (Arid zone), Nigeria. Vet Arhiv. 2010;80:283-97.
37. Neher S, Hazarika A, Barkalita L, Borah P, Bora D, Sharma R. Isolation and characterization of Shiga toxigenic Escherichia coli of animal and bird origin by multiplex polymerase chain reaction. Vet World. 2016;9:123.

38. Ayaz ND, Copuroglu G, Ormeci E, Oz B. Presence of Staphylococcus aureus and Shiga Toxigenic Escherichia coli O157: H7 in Raw Meat in Ağrı Turkey. Int J Enteric Pathog. 2016;4:e36523.

39. Franz E, Klerks MM, De Vos OJ, Termorshuizen AJ, van Bruggen AH. Prevalence of Shiga toxin-producing Escherichia coli stx1, stx2, eaeA, and fbE genes and survival of E. coli O157: H7 in manure from organic and low-input conventional dairy farms. Appl Environ Microbiol. 2007;73:2180-90.

40. Jay-Russell MT, Hake AF, Bengson Y, Thiptara A, Nguyen T. Prevalence and characterization of Escherichia coli and Salmonella strains isolated from stray dog and coyote feces in a major leafy greens production region at the United States-Mexico border. Plos One. 2014;9:e113433.

41. Kabiru LM, Bello M, Kabir J, Grande L, Morabito S. Detection of pathogenic Escherichia coli in samples collected at an Abattoir in Zaria, Nigeria and at different points in the surrounding environment. Int J Environ Res Public Health. 2015;12:679-91.

42. Momtaz H, Safarpoor Dehkordi F, Taktaz T, Rezvani A, Yarali S. Shiga toxin-producing Escherichia coli isolated from bovine mastitic milk: serogroups, virulence factors, and antibiotic resistance properties. Sci World J. 2012;2012:618709.

\section{Submit your next manuscript to BioMed Central and we will help you at every step:}

- We accept pre-submission inquiries

- Our selector tool helps you to find the most relevant journal

- We provide round the clock customer support

- Convenient online submission

- Thorough peer review

- Inclusion in PubMed and all major indexing services

- Maximum visibility for your research

Submit your manuscript at www.biomedcentral.com/submit
C Biomed Central 